\title{
Stimulation and characteristics of secondary oesophageal peristalsis in normal subjects
}

\author{
M N Schoeman, R H Holloway
}

\begin{abstract}
The study evaluates the triggering and characteristics of secondary oesophageal peristalsis in $\mathbf{2 5}$ healthy volunteers. Secondary peristalsis was stimulated by rapid intraoesophageal injection of boluses of air and water, and by a five second oesophageal distension with a ballon. Air and water boluses triggered secondary peristalsis that started in the proximal oesophagus regardless of injection site. Response rates were volume dependent with $83 \%$ of the $20 \mathrm{ml}$ air boluses triggering secondary peristalsis compared with $2 \%$ for the $2 \mathrm{ml}$ water bolus $(\mathbf{p}<\mathbf{0 . 0 0 0 1})$. Response rates for air and water were similar for equal bolus volumes and were not influenced by the site of injection. In contrast, balloon distension usually induced a synchronous contraction above the balloon, with secondary peristalsis starting below the balloon after deflation. The peristaltic response rate to balloon distension was also volume dependent and the middle balloon was more effective in triggering secondary peristalsis than either the upper or lower balloons $(\mathbf{p}<0.001)$. Secondary peristaltic amplitude was less than that of primary peristalsis $(\mathbf{p}<0.001)$. Secondary peristaltic velocity with a water bolus was slower $(p=0.001)$ than that of primary peristalsis. Intravenous atropine significantly reduced secondary peristaltic responses to all stimuli. There was also a significant reduction in pressure wave amplitude for air stimulated secondary peristalsis while those for the water responses were similar. Secondary peristaltic velocity with air and water boluses was not changed by atropine. The reproducibility of testing secondary peristalsis was examined six volunteers and did not show any significant differences on separate test days in response rate and peristaltic amplitude or velocity. It is concluded that in normal subjects, secondary peristalsis can be more reliably triggered by intraoesophageal air or water infusion than balloon distension. Secondary peristaltic amplitude and velocity are stimulus but not site or volume dependent and propagation is partially mediated by cholinergic nerves.

(Gut 1994; 35: 152-158)
\end{abstract}

Secondary peristalsis occurs in response to oesophageal distension. Physiologically this occurs if food, fluid or air are retained in the oesophagus after a failed primary peristaltic wave or after reflux from the stomach. Functionally, it is of protective importance in maintaining an empty oesophagus by clearing the bulk of the volume of the refluxate after a reflux event. ${ }^{1}$ This assists the return to normal values of oesophageal $\mathrm{pH}$ by primary peristalsis and swallowed saliva by preventing prolonged contact time between refluxed gastric acid and the oesophageal mucosa.

Considerable data are available in published works about primary peristalsis with regard to its reproducibility, contraction characteristics, and abnormalities in various disease states. ${ }^{34}$ Secondary peristalsis, on the other hand, has received comparatively limited attention. Meltzer first defined secondary peristalsis in animal experiments in $1906 . .^{5}$ Since then, stimuli such as oesophageal balloon distension and air or water infusion have been studied but differences in distension volume, level of infusion, and duration of distension make comparison of the results difficult. $^{6-12}$ In addition, early studies sampled comparatively few points in the oesophagus and used manometric techniques with low : scording fidelity that impair the validity of data on peristaltic amplitude and velocity. Recent studies have investigated oesophageal responses to prolonged balloon distension ${ }^{13}$ and slow intraoesophageal infusion of liquid ${ }^{2}{ }^{14}$ but these did not examine the secondary peristaltic responses in detail. The most appropriate method of triggering secondary peristalsis and the normal ranges for peristaltic amplitude and velocity, therefore, remain to be adequately defined.

The aims of our study were to test the efficacy of different distending stimuli within the oesophagus to establish a reliable means of examining secondary peristalsis and to define the distension induced oesophageal motor responses in healthy subjects as a prelude to the evaluation of patients with suspected oesophageal body motor dysfunction.

\section{Subjects and methods}

\section{SUBJECTS}

We studied 25 healthy subjects (11F:15M) ranging in age from 19-40 years (median 21). Subjects were free of any gastrointestinal symptoms, had no history of upper gastrointestinal surgery, and were not taking antacids on a regular basis. No subject took any drugs 
known to change oesophageal motor function. Each volunteer gave written informed consent and the study was approved by the human ethics committee of the Royal Adelaide Hospital.

\section{MANOMETRY}

Oesophageal motility was recorded with a multilumen manometric catheter with an outside diameter of $4.5 \mathrm{~mm}$. Side holes, spaced at $3 \mathrm{~cm}$ intervals starting at $2 \mathrm{~cm}$ above the proximal margin of the lower oesophageal sphincter, monitored pressures at seven sites along the oesophageal body. A side hole in the pharynx recorded swallowing. Catheter position was maintained by taping the catheter to the nose. The oesophageal side holes were perfused with degassed distilled water at $0.6 \mathrm{ml} / \mathrm{min}$, and the pharyngeal side hole at $0.3 \mathrm{ml} / \mathrm{min}$ by a low compliance pneumohydraulic capillary infusion system. ${ }^{15}$ Pressures were sensed by external pressure transducers (Deseret Medica Inc, Park Davis \& Co, Sandy, Utah, USA, Model 38$8000-1)$ with output to a 12 channel polygraph recorder (Grass Instrument Co, Quincy, MA, USA, Model 7D). Recordings were made at a paper speed of $5 \mathrm{~mm} / \mathrm{s}$.

Two manometric assemblies were used. One had three silicone rubber balloons for distension of the upper, middle, and lower oesophagus. The other assembly had three infusion ports, corresponding to the position of the balloons, for the rapid injection of boluses of air or water. The infusion ports and the centre of the balloons were located at $6 \cdot 5,12 \cdot 5$, and $18 \cdot 5 \mathrm{~cm}$ above the lower oesophageal sphincter.

\section{STUDY PROTOCOL}

Subjects were studied after an overnight fast. After positioning of the manometric assembly and a 10 minute adaptation period, each subject was assessed for both primary and secondary peristalsis. Primary peristalsis was tested with $10,5 \mathrm{ml}$ water swallows and 10 dry swallows. Each swallow was separated by a 30 second interval.

Secondary peristalsis was triggered by oesophageal distension using three stimuli. In 10 subjects the oesophagus was distended by balloons that were inflated for five seconds to diameters of 1,2 , and $3 \mathrm{~cm}$, corresponding to volumes of $1,4.5$, and $17 \mathrm{ml}$ respectively. In a further 10 subjects, 2,5 , and $10 \mathrm{ml}$ boluses of water and 5, 10, and $20 \mathrm{ml}$ boluses of air were injected rapidly by hand into the oesophagus at levels corresponding to those of the balloons. One subject took part in both protocols. The rate of injection was determined by the volume and viscosity of the stimulus used. The $10 \mathrm{ml}$ water bolus was injected within 1.5 seconds while the injection of the boluses of air was more rapid with the $20 \mathrm{ml}$ bolus injected within 0.5 seconds. Each stimulus was tested in triplicate and was separated by an interval of at least 15 seconds from any preceding primary peristaltic activity. An interval of 20 seconds was permitted after each test for any response to occur. During this time the subjects were instructed not to swallow. After 20 seconds, each stimulus was followed by a dry swallow to clear any residual air or water and reduce the desire to swallow. Subjects were then given intravenous atropine in a bolus dose of $15 \mu \mathrm{g} / \mathrm{kg}$ followed by an intravenous infusion at $4 \mu \mathrm{g} / \mathrm{kg} /$ hour, ${ }^{16}$ and the stimuli retested in triplicate. The degree of cholinergic blockade was monitored at 15 minute intervals by assessment of pulse rate, pupillary dilatation, and the subject's reporting of mouth dryness and visual blurring. Mouth dryness was self reported and scored on a scale of $0-10$ with normal being rated at 10 and very dry as zero.

The reproducibility of testing primary and secondary peristalsis was examined in six subjects. Primary peristalsis was tested using water swallows and secondary peristalsis was triggered with rapid bolus injection of $10 \mathrm{ml}$ of air and water into the mid oesophagus. Each stimulus was repeated 10 times and the study performed twice at least one week apart.

\section{DATA ANALYSIS}

The contraction amplitude at each recording site and the latency of the wave onset between adjacent recording sites were measured for both primary and secondary peristalsis. Amplitude was measured from basal and expiratory intraoesophageal pressure to the peak of the pressure wave. The onset of the major upstroke of the pressure wave was used as the reference point for determination of the wave latency.

Primary peristalsis was classified as complete if a propagated pressure of $\geqslant 12 \mathrm{~mm} \mathrm{Hg}$ in the proximal two oesophageal body channels $\geqslant 25 \mathrm{~mm} \mathrm{Hg}$ in the distal five oesophageal channels, traversed all the recording sites. ${ }^{17}$ The minimum latency of wave onset between adjacent recording sites that defined peristaltic progression was set at 0.5 seconds, corresponding to a peristaltic velocity of $6 \mathrm{~cm} / \mathrm{s}$. Criteria for failed peristalsis were either failure of a pressure wave, $\geqslant 12 \mathrm{~mm} \mathrm{Hg}$ in the proximal two oesophageal channels and $\geqslant 25 \mathrm{~mm} \mathrm{Hg}$ in the distal five channels, to traverse each of the oesophageal recording sites or synchronous

TABLE I Manometric characteristics of primary and secondary peristalsis

\begin{tabular}{lll}
\hline Stimulus & $\begin{array}{l}\text { Amplitude } \\
(\mathrm{mm} \mathrm{Hg})\end{array}$ & $\begin{array}{l}\text { Velocity } \\
(\mathrm{cm} / \mathrm{s})\end{array}$ \\
\hline $\begin{array}{l}\text { Primary peristalsis } \\
\text { Water swallows }\end{array}$ & $88 \cdot 9(2 \cdot 1)$ & $2 \cdot 9(0 \cdot 04)$ \\
$\begin{array}{l}\text { Secondary peristalsis } \\
\text { Air }\end{array}$ & & \\
$5 \mathrm{ml}$ & $72 \cdot 3(3 \cdot 9)$ & $2 \cdot 8(0 \cdot 14)$ \\
$10 \mathrm{ml}$ & $72 \cdot 9(2 \cdot 6)$ & $2 \cdot 9(0 \cdot 10)$ \\
$20 \mathrm{ml}$ & $74 \cdot 6(2 \cdot 4)$ & $3 \cdot 1(0 \cdot 10)$ \\
Mean (all volumes) & $73 \cdot 6(1 \cdot 6)^{\star}$ & $2 \cdot 9(0 \cdot 06)$ \\
Water & $\mathrm{n} / \mathrm{a}$ & $\mathrm{n} / \mathrm{a}$ \\
$2 \mathrm{ml}(\mathrm{n}=2)$ & $59 \cdot 4(3 \cdot 0)$ & $2 \cdot 8(0 \cdot 14)$ \\
$5 \mathrm{ml}$ & $66 \cdot 7(2 \cdot 6)$ & $2 \cdot 5(0 \cdot 07) \dagger$ \\
$10 \mathrm{ml}$ & $63 \cdot 6(2 \cdot 0)^{\star}$ & $2 \cdot 6(0 \cdot 07) \ddagger$ \\
Mean (all volumes) & & \\
Balloon & $\mathrm{n} / \mathrm{a}$ & $\mathrm{n} / \mathrm{a}$ \\
$1 \mathrm{~cm}(\mathrm{n}=1)$ & $59 \cdot 1(8 \cdot 6)$ & $2 \cdot 5(0 \cdot 38)$ \\
$2 \mathrm{~cm}$ & $64 \cdot 8(5 \cdot 4)$ & $2 \cdot 9(0 \cdot 30)$ \\
$3 \mathrm{~cm}$ & $64 \cdot 0(4 \cdot 3)^{\star}$ & $2 \cdot 7(0 \cdot 23)$ \\
Mean (all diameters) & & \\
\hline
\end{tabular}

Data expressed as mean (SEM); ${ }^{\star} \mathrm{p}=0.0001$ compared with water swallow amplitude; $t \mathrm{p}=0.04$ compared with $5 \mathrm{ml}$ water responses; $\neq p=0.01$ compared with primary peristaltic velocity; $\mathrm{n} / \mathrm{a}=$ not analysable 
pressure waves occurring at two or more recording sites. In addition, no response to distension was judged to have occurred if a pressure wave $\geqslant 10 \mathrm{~mm} \mathrm{Hg}$ was seen in less than two recording sites. For complete peristaltic responses, mean amplitude and velocity were calculated for the five distal recording sites corresponding to the distal $12 \mathrm{~cm}$ of the oesophageal body.

Secondary peristalsis in response to air and water bolus injection was typically characterised by a propagated pressure wave and traversed the entire oesophagus, and was analysed in the same manner as primary peristalsis. Secondary peristalsis associated with balloon distension, however, was characterised by separate responses above and below the balloon and each component was analysed individually using the same criteria as for primary peristalsis.

\section{STATISTICAL ANALYSIS}

For each stimulus, response rates were determined for each subject. Additionally, data for all tests in all subjects were combined. The differences in response rates between stimuli were analysed using a $\chi^{2}$ test, and peristaltic amplitude and velocity were compared using analysis of variance. Differences among sites for each stimulus were compared using log linear modelling techniques. ${ }^{19}$ Retest reliability of primary and secondary peristalsis was examined using multivariate analysis for single sample matched pairs. ${ }^{20}$ Data in the text are expressed as mean (standard error of the mean).

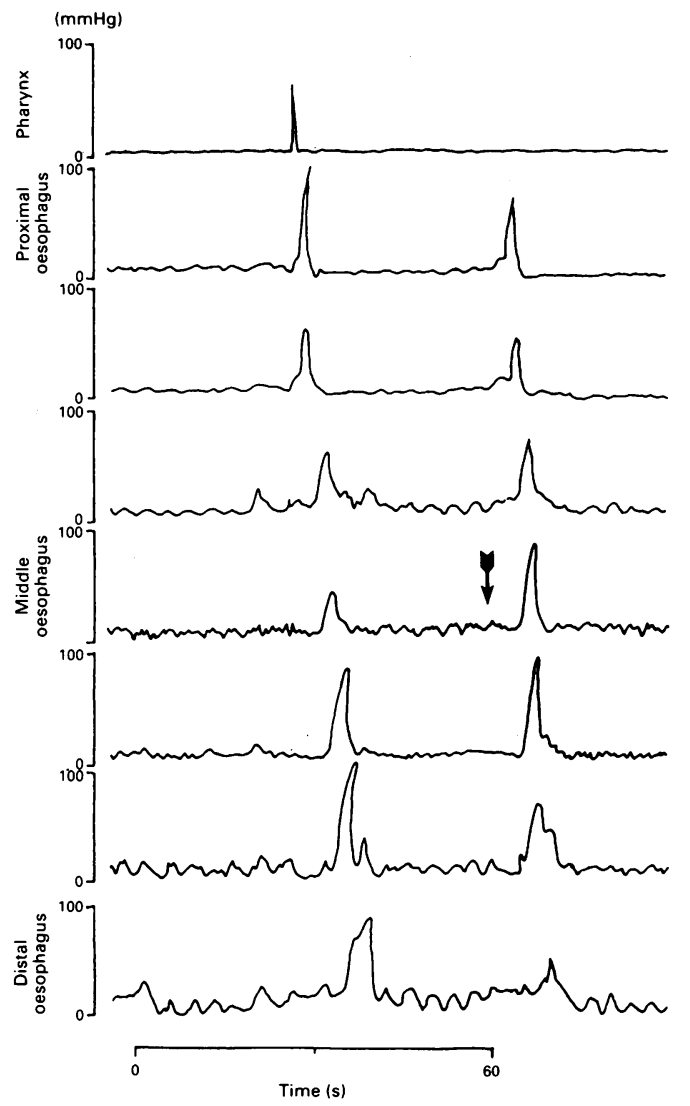

Figure 1: Pressure tracing showing primary peristalsis triggered by a water swallow and secondary peristalsis triggered by a $10 \mathrm{ml}$ air bolus injection. The position of the arrow shows the time and level of bolus injection.

\section{Results}

PRIMARY PERISTALSIS

In all subjects, complete primary peristalsis occurred with at least eight of 10 water swallows. The mean success rate was $96 \%$. Table I summarises the pressure wave amplitudes and propagation velocities.

\section{SECONDARY PERISTALSIS}

\section{Air and water boluses}

Both air and water boluses produced complete secondary peristaltic responses that, regardless of the level of injection, started at the most proximal oesophageal recording site and traversed the entire length of the oesophageal body (Fig 1). For both air and water boluses, the response rate of complete peristalsis increased significantly as the injected volume increased $(\mathrm{p}<0.0001$, Fig 2) and were similar for air and water boluses of equal volume. In addition, when equal bolus volumes of air and water were compared, the level of injection did not influence the number of complete peristaltic responses $(\mathrm{p}=0.4$, Fig 3).

Table I summarises the mean pressure wave amplitude and propagation velocity. The amplitudes of secondary peristalsis stimulated by air and water were less than that of primary peristalsis. Propagation velocity of secondary peristalsis stimulated by air was similar to that of primary peristalsis while secondary peristalsis stimulated by water was slower than primary peristalsis. The three volumes of air triggered pressure waves of similar amplitude as did the 5 $\mathrm{ml}$ and $10 \mathrm{ml}$ water boluses. The $2 \mathrm{ml}$ water bolus, however, triggered only two peristaltic responses. Propagation velocities for all three volumes of air stimulated secondary peristalsis were similar, while the propagation velocity with the $10 \mathrm{ml}$ bolus of water was less than that stimulated by the $5 \mathrm{ml}$ bolus ( $\mathrm{p}=0 \cdot 04)$.

\section{Balloon distension}

Balloon distension produced a different pattern of secondary peristalsis from that of the air or water boluses (Fig 4). Characteristically, during distension there was a high amplitude synchronous contraction above the balloon while below there was motor quiescence. After distension, the synchronous contraction above the balloon subsided and a peristaltic contraction wave progressed distally from the level of the balloon. Peristalsis above the balloon was rare and occurred with only two of 270 balloon distensions. Figure 5 shows the response rates for the different motor components. The ability to trigger secondary peristalsis below the balloon was volume dependent with a $3 \mathrm{~cm}$ distension more likely to elicit a response than a $1 \mathrm{~cm}$ distension $(p=0.004)$. In addition, the middle balloon was more likely to stimulate a peristaltic response than the upper or lower balloons ( $p=0.04$, Fig 6$)$. The amplitude of secondary peristalsis elicited by balloon distension was less than that of primary peristalsis, while propagation velocity was similar (Table I). 


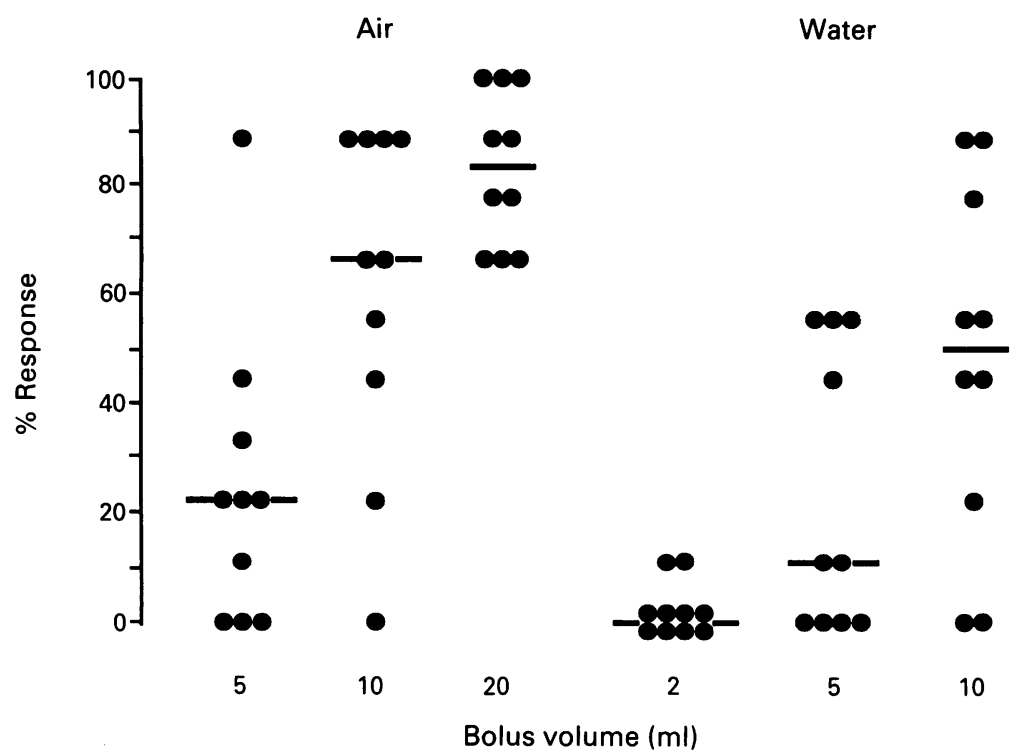

Figure 2: Effect of bolus volume on the secondary peristaltic responses to air and water. Data for the three oesophageal sites are combined with each volume tested nine times in each subject. Overall response rates for each individual subject are shown by the dots and median response rates are shown by the bars. The frequency of secondary peristaltic responses increased significantly with bolus volume $(p<0.0001)$.

Balloon volume did not influence the amplitude or propagation velocity of the peristaltic responses triggered by the $2 \mathrm{~cm}$ and $3 \mathrm{~cm}$ balloons ( $p>0.05)$. The manometric responses induced by the $1 \mathrm{~cm}$ balloon could not be compared because of the limited number of responses.

\section{REPRODUCIBILITY}

Intrasubject secondary peristaltic response rates did not differ significantly between the first and second test days (Table II). Similarly, the pressure wave amplitude and velocity of secondary peristalsis was the same on the first and second test days.

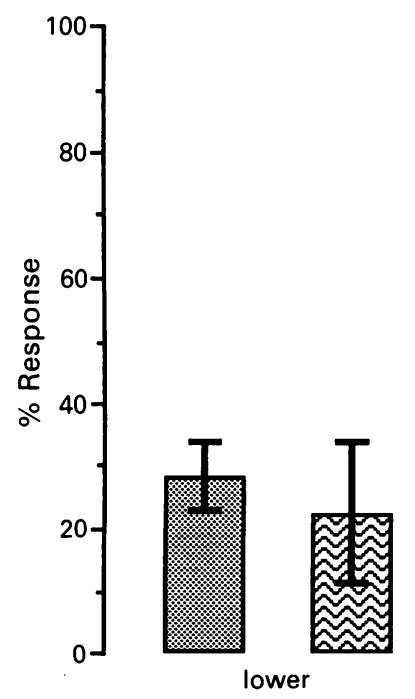

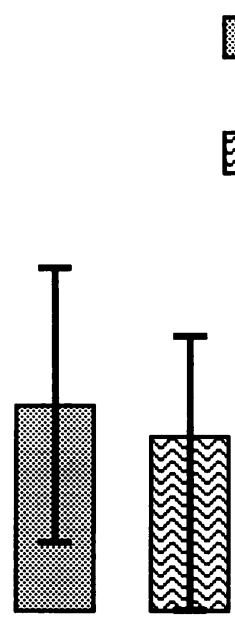

middle
Air

园 Water

Injection site

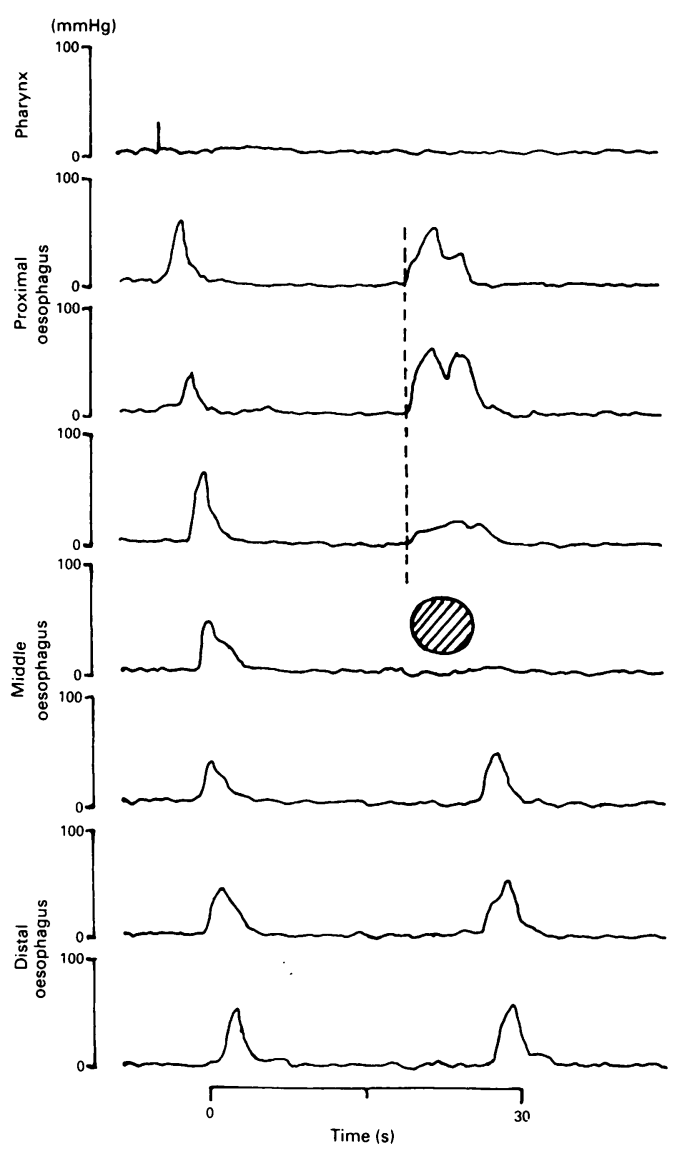

Figure 4: Pressure tracing showing primary peristalsis triggered by a water swallow and secondary peristalsis triggered by balloon distension. The position of the schematic balloon illustrated shows the level and duration of balloon distension.
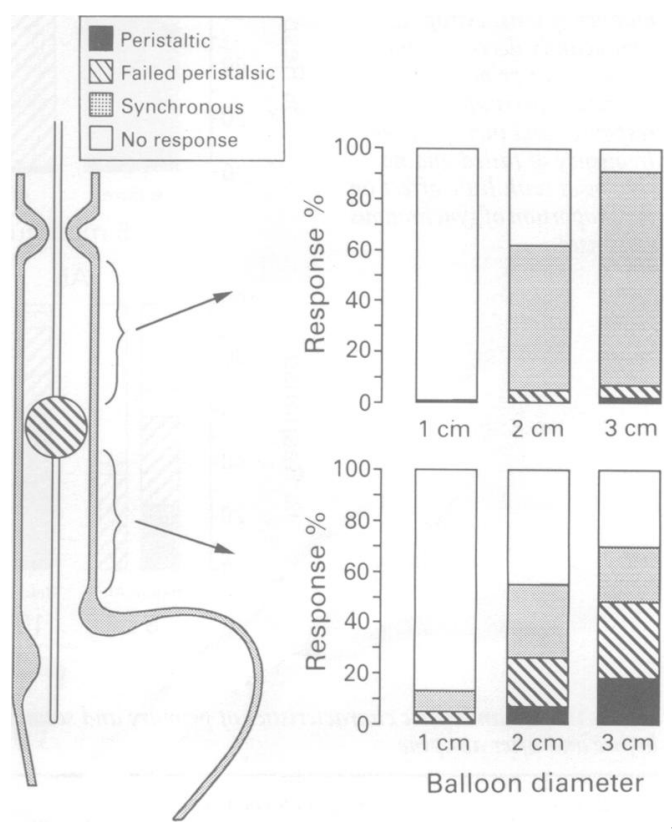

Balloon diameter

Figure 5: Manometric responses to oesophageal balloon distension. Responses have been characterised separately above and below the balloon for the three distension volumes. above and below the balloon for the three distension volumes. the responses below the balloon occurred after deflation. Data for the three sites have been combined and expressed as a percentage of the total number of tests. Each diameter was tested in triplicate at three levels in the oesophagus in 10

volunteers giving a total of 90 tests. The frequency of secondary peristaltic responses increased significantly with balloon volume $(p=0.004)$.

Figure 3: Effect of the site of injection on the proportion of secondary peristaltic responses to a ir and water boluses. Combined data for the 5 and $10 \mathrm{ml}$ boluses are shown. The column represents the median frequency of secondary peristaltic responses for each stimulus at each site and the interval lines show the interquartile range. The 5 and $10 \mathrm{ml}$ volumes were tested in triplicate in 10 volunteers giving a total of 60 tests at each level. The frequency of responses for air and water boluses were similar at each site. 
Figure 6: Effect of site of balloon distension on secondary peristaltic responses. Data for the three volumes have been combined. Each column represents the proportion of peristaltic responses, expressed as a percentage of the total number of tests. The three diameters were tested in triplicate in 10 volunteers giving a total of 90 tests at each level. The middle balloon was more likely to trigger secondary peristalsis than the upper or lower sites $\left({ }^{\star} p=0.04\right)$.

Figure 7: Effect of atropine on the pattern of primary peristalsis and secondary peristaltic responses to water, air, and balloon distension. Data for the three sites of stimulation of secondary peristalsis have been combined and frequency of response is expressed as a percentage of the total number of tests. Atropine significantly decreased the frequency of primary and secondary peristaltic responses and increased the frequency of failed and no responses with little effect on responses with little effect on
the proportion of synchronous responses.

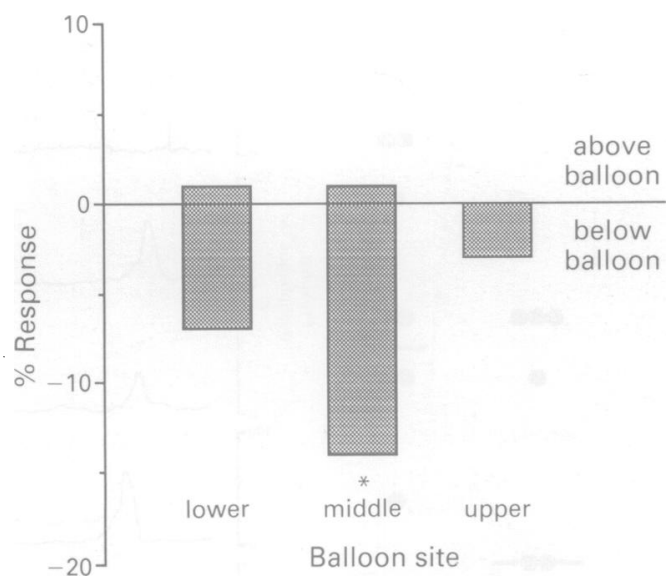

TABLE II Reproducibility of secondary peristalsis

\begin{tabular}{lcc}
\hline & Test 1 & Test 2 \\
\hline Response rate & & \\
Air & $2 \cdot 5(1-6)$ & $4 \cdot 5(0-7)$ \\
Water & $1 \cdot 0(0-5)$ & $3 \cdot 5(0-9)$ \\
Amplitude $(\mathrm{mm} \mathrm{Hg}) \dagger$ & $76 \cdot 6(5 \cdot 8)$ & $71 \cdot 4(4 \cdot 7)$ \\
$\quad$ Air & $66 \cdot 1(3 \cdot 6)$ & $66 \cdot 0(4 \cdot 0)$ \\
Water & $3 \cdot 1(0 \cdot 15)$ & $3 \cdot 3(0 \cdot 11)$ \\
Velocity $(\mathrm{cm} / \mathrm{s}) \dagger$ & $2 \cdot 8(0 \cdot 10)$ & $3 \cdot 0(0 \cdot 11)$ \\
Air & & \\
Water &
\end{tabular}

$\star$ Data expressed as median (interquartile range); $†$ Data are expressed as mean (SEM).

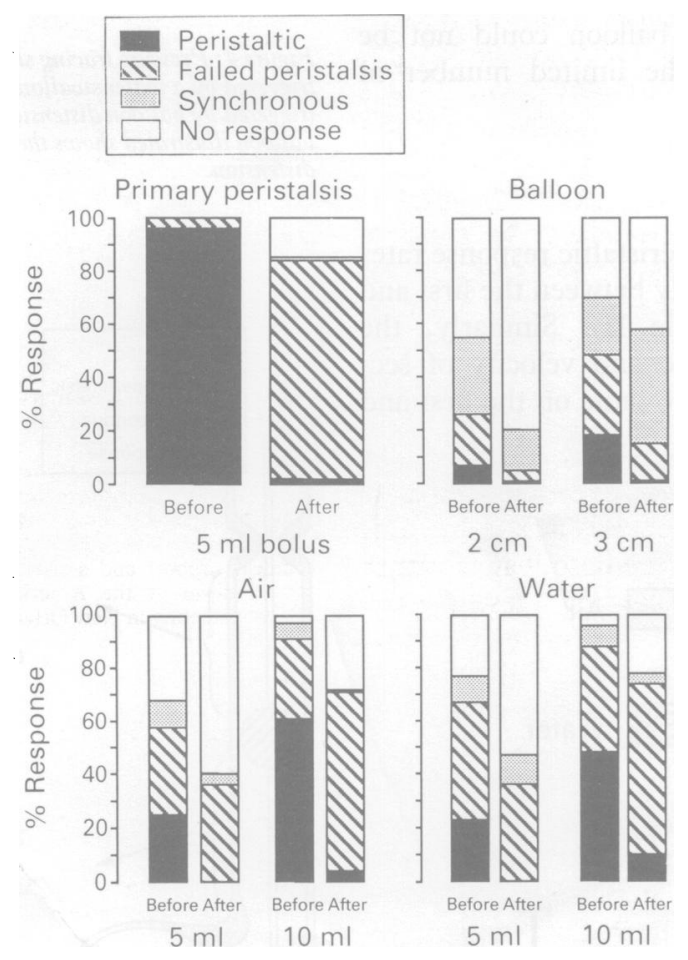

TABLE III Manometric characteristics of primary and secondary peristaltic pressure waves before and after atropine

\begin{tabular}{|c|c|c|c|c|}
\hline \multirow[t]{2}{*}{ Stimulus } & \multicolumn{2}{|c|}{ Amplitude (mm Hg) } & \multicolumn{2}{|c|}{ Velocity $(\mathrm{cm} / \mathrm{s})$} \\
\hline & $\begin{array}{l}\text { Before } \\
\text { atropine }\end{array}$ & $\begin{array}{l}\text { After } \\
\text { atropine }\end{array}$ & $\begin{array}{l}\text { Before } \\
\text { atropine }\end{array}$ & $\begin{array}{l}\text { After } \\
\text { atropine }\end{array}$ \\
\hline \multirow{2}{*}{$\begin{array}{l}\text { Primary peristalsis } \\
\text { Water swallows` } \\
\text { Secondary peristalsis† } \\
\text { Air } \\
\text { Water } \\
\text { Balloon }\end{array}$} & $88 \cdot 9(2 \cdot 1)$ & $\mathbf{n} / \mathbf{a}$ & $2.9(0.04)$ & $\mathbf{n} / \mathbf{a}$ \\
\hline & $\begin{array}{l}73 \cdot 6(1 \cdot 6) \\
63 \cdot 6(2 \cdot 0) \\
64 \cdot 0(4 \cdot 3)\end{array}$ & $\begin{array}{l}50 \cdot 9(3 \cdot 7) \ddagger \\
54 \cdot 9(4 \cdot 3) \\
\text { n/a }\end{array}$ & $\begin{array}{l}2.9(0.06) \\
2.6(0.07) \\
2.7(0.23)\end{array}$ & $\begin{array}{l}3 \cdot 2(0.51) \\
2 \cdot 4(0.36) \\
\mathrm{n} / \mathrm{a}\end{array}$ \\
\hline
\end{tabular}

Data are expressed as mean (SEM); ${ }^{\star}$ triggered only two responses after atropine; †all volumes combined; $¥ p=0.0002$ compared with before atropine; $n / a=$ not analysable

ATROPINE

All subjects showed clinical features of muscarinic blockade after the loading dose and throughout the duration of the atropine infusion. Clinical assessment 15 minutes after the start of the atropine infusion showed a significant increase in pulse rate (before 69 (3) beats/min, after: 108 (3) beats/min, $\mathrm{p}=0.0001$ ), mouth dryness (before: $8 \cdot 5$, after: $2, \mathrm{p}=0 \cdot 0001$ ), and pupillary dilatation (before: $4 \cdot 0(0 \cdot 2) \mathrm{mm}$, after: $4.85(0 \cdot 3) \mathrm{mm}, \mathrm{p}=0.02)$.

Atropine significantly reduced the rate of complete peristaltic responses to all the stimuli (Fig 7). Primary peristalsis and the secondary peristaltic responses to $5 \mathrm{ml}$ air and water boluses were virtually abolished. The reduction in secondary peristalsis was associated with an increase in the frequency of failed and no responses with the frequency of synchronous responses remaining unchanged. The effect of atropine on the distension induced responses below the balloon was similar to that of the responses to air and water distension (Fig 7). Above the balloon, atropine significantly reduced the frequency of synchronous responses to balloon distension at all sites with a decrease in mean response frequency from 47 to $18 \%$ $(\mathrm{p}<0.01)$.

Atropine significantly reduced the amplitude of secondary peristalsis to the air but not water boluses. The number of primary peristaltic responses and secondary peristaltic responses to balloon distension, however, was too few to permit statistical comparison (Table III). Atropine reduced the amplitudes of the synchronous responses above the middle and lower balloon but had no effect on the amplitude of the synchronous responses above the upper balloon. Atropine had no effect on the propagation velocities for secondary peristalsis.

\section{Discussion}

Although it has been almost 90 years since Meltzer's original description of secondary peristalsis, ${ }^{3}$ remarkably little data exist in published works about the phenomenon. Debate persists about the nature of the oesophageal response and its similarity to primary peristalsis. ${ }^{12}{ }^{21}$ In this study we examined the oesophageal responses to distension using high fidelity manometry that gave accurate measurement and sensitive spatial resolution of pressures, and investigated the effect of site and volume on the response to three different stimuli. Our findings establish that, with an appropriate stimulus, a secondary peristaltic response can be evoked that has similar manometric characteristics to those of primary peristalsis. The response is reproducible and can be readily incorporated into diagnostic clinical manometric studies.

Our results show that the oesophageal response to distension is variable and influenced by the type of stimulus. When the oesophagus is distended with air or water boluses, a peristaltic response that traverses the entire oesophagus is produced. In contrast, the response to balloon distension is usually characterised by synchronous contractions above the balloon; secondary peristalsis is uncommon and occurs 
predominantly below the distension point after deflation. This variability in the response to oesophageal distension explains, at least in part, the conflicting results of previous studies, and shows that oesophageal responses to distention can only be considered in the context of a specified stimulus.

The variability of the response probably arises from the behaviour of the stimulus. The balloon provides a focal stimulus that cannot be moved by any induced motor response. In contrast, air and water disperse along the oesophagus and can be moved ahead of any induced propagated wave. The moving bolus may also serve to reinforce the response in a manner similar to that of water swallows in primary peristalsis. ${ }^{322} 23$ Previous studies suggest that stimulation of the striated muscle segment of the oesophagus may be an important factor in triggering secondary peristalsis through activation of a central reflex pathway. ${ }^{2124}$. The air and water boluses invariably induced a small common cavity pressure rise throughout the oesophagus at the time of injection showing that the striated muscle segment was distended whatever the site of injection. The effect was not seen with balloon distension which, in the case of the distal two balloons, would be confined to the smooth muscle segment. Interestingly, however, the balloon distension at the mid oesophagus, was significantly better at stimulating peristalsis than when applied to the upper oesophagus. The reason for this difference is not clear but may relate to the transition from striated to smooth muscle at this level.

The manometric characteristics of complete secondary peristalsis were similar to those to primary peristalsis suggesting common neural mechanisms. In contrast with earlier findings, ${ }^{12} 21$ peristaltic velocity with balloon distension was similar to that for air and water distension and for primary peristalsis. This discrepancy may be explained by differences in data analysis, with our analysis being limited to the mean velocity of the peristaltic responses over the distal $12 \mathrm{~cm}$ of the oesophagus rather than between adjacent recording sites. We did not calculate regional differences as the time intervals between contractions at adjacent side holes spaced $3 \mathrm{~cm}$ apart, recorded at a paper speed of $5 \mathrm{~mm} / \mathrm{s}$, were beyond the limits of accurate resolution using manual analysis. Peristaltic velocity was not influenced by balloon diameter or the size of the air boluses but was slower for the largest water bolus. A similar effect has been seen with primary peristalsis ${ }^{25}$ and suggests sensory feedback from the oesophageal wall to the intramural neural mechanisms underlying the peristaltic response.

Atropine reduced the frequency of seconday peristalsis triggered by all three stimuli. This effect seemed to be largely a result of a reduction in pressure wave amplitude as the pattern of failure after atropine was usually characterised by focal low amplitude contractions rather than a change in peristaltic velocity or complete peristaltic failure. This response to atropine is consistent with an effect at the level of the smooth muscle. ${ }^{26}$ Similar findings have been made in the cat. ${ }^{24}$ This reduction in peristaltic response rate might also be explained by either increased oesophageal compliance induced by atropine with subsequent reduction in the number of oesophageal stretch receptors triggered or failure to detect weak non-lumen occluding peristaltic responses. ${ }^{27}$

Atropine also decreased the amplitude of the synchronous responses above the balloon. This reduction, however, was seen only with the middle and distal balloons and may reflect inclusion of responses from the proximal part of the smooth muscled portion of the oesophagus. It may also be because of a reduction in the intensity of the stimulus resulting from the effects of atropine on the oesophageal smooth muscle at the site of distension. Consistent with an earlier report, ${ }^{21}$ atropine did not affect the amplitude of the synchronous responses induced in the striated segment of the oesophagus above the proximal balloon.

Secondary peristalsis is an important mechanism for the clearance of retained material or refluxate from the oesophagus ${ }^{28}$ and defective secondary peristalsis might be a mechanism contributing to the pathogenesis of reflux disease or dysphagia. Measurement of secondary peristalsis could thus be useful in assessing these problems. We have shown that it can be easily and reliably tested by injecting air or water boluses through the manometric catheter. The reproducibility of the response is excellent with no significant variation in response rates or manometric characteristics between test days. While balloons have been the traditional means of testing secondary peristalsis, our findings suggest that they are an inferior stimulus and, from a practical point of view, they are susceptible to damage.

This project was supported by a project grant from the National Health and Medical Research Council. Dr Schoeman is supported by a National Health and Medical Research Council postgraduate scholarship with additional maintenance funds provided by a Royal Adelaide Hospital Dawes scholarship. The valuable support and assistance of Professor John Dent in the development of the recording apparatus and for reviewing the manuscript is gratefully acknowledged. The authors also thank Mr Marcus Tippett for his technical support and assistance. This study was presented in abstract form at the American Gastroenterology Association scientific meeting in New Orleans, May 1991.

1 Helm JF, Dodds WJ, Pelc LR, Palmer DW, Hogan WJ Teeter BC. Effect of esophageal emptying and saliva on
clearance of acid from the esophagus. $N E$ ngl $\mathcal{F}$ Med 1984; 310: $284-8$.

2 Corazziari E, Pozzessere C, Dani S, Anzini F, Torsoli A. Intraluminal $\mathrm{pH}$ and esophageal motility. Gastroenterology 1978; 75: 275-7.

3 Dodds WJ, Hogan WJ, Reid DP, Stewart ET, Arndorfer RC A comparison between primary esophageal peristalsis following wet and dry swallows. F Appl Physiol 1973; 35: 851-7.

4 Richter JE, Wu WC, Johns DN, et al. Esophageal manometry in 95 healthy adult volunteers. Dig $D$ is $S c i$ 1987; 32: 583-92.

5 Meltzer SJ. Secondary peristalsis of the esophagus - a demonstration on a dog with a permanent esophageal fistula. Proc

Soc Exp Biol Med 1906; 3: 35-7.
6 Meltzer SJ. On the nature of the reflexes controlling the successive movements in the mechanism of deglutition. Proc Soc Exp Biol Med 1906-7; 3: 52-5.

7 Dornhurst AC, Harrison K, Pierce JW. Observations on the normal oesophagus and cardia. Lancet 1954; i: 695-8.

8 Creamer B, Schlegel J. Motor responses of the esophagus to distension. F Appl Physiol 1957; 10: 498-504.

9 Fleschler B, Hendrix TR, Kramer P, Ingelfinger FJ. The characteristics and similarity of primary and secondary peristalsis in the esophagus. F Clin Invest 1959; 38: 110-6.

10 Siegel CI, Hendrix TR. Evidence for the central mediation of secondary peristalsis in the esophagus. Bull fohns Hopkins Hosp 1961; 108: 297-307.

11 Winship DH, Zboralske FF. The esophageal propulsive force: esophageal response to acute obstruction. $\mathcal{F}$ Clin Invest 1967 46: 1391-401. 
12 Paterson WG, Rattan S, Goyal RK, Esophageal responses to transient and sustained esophageal distention. Am $\mathcal{F}$ Physiol 1988; 255: G587-95.

13 Williams D, Thompson DG, Marples M, et al. Identification of an abnormal esophageal clearance response to intraluminal distension in patients with esophagitis. Gastroenterology 1992; 103: 943-53.

14 Thompson DG, Andreollo NA, McIntyre AS, Earlam RJ. Studies of the oesophageal clearance responses to intraStudies of the oesophageal clearan
luminal acid. Gut $1988 ; 29: 881-5$

15 Arndorfer RC, Stef JJ, Dodds WJ, Linehan JH, Hogan WJ Improved infusion system for intraluminal esophageal manometry. Gastroenterology 1977; 73:23-7.

16 Dodds WJ, Dent J, Hogan WJ, Arndorfer RC. Effect of atropine on esophageal motor function in humans. Am $\mathcal{f}$ Physiol 1981; 240: G290-6.

17 Kahrilas PJ, Dodds WJ, Hogan WJ. Effect of peristaltic dysfunction on esophageal volume clearance. Gastroenterology 1988; 94: 73-80.

18 Hewson E, Ott D, Dalton C, Chen Y, Wu W, Richter J. Manometry and radiology. Complementary studies in the assessment of esophageal motility disorders. Gastroenterology 1990; 98: 626-32.

19 Bishop YMM, Fienberg SE, Holland PW. Discrete multivariate analysis: theory and practice. Cambrdige, MA: The variate analysis: thed
MIT Press, 1975.

20 Brunning JL, Kintz BL. Computational handbook of statistics. 3rd ed. Glenview, Illinois: Harper Collins, 1987.

21 Paterson W, Hynna-Liepert T, Selucky M. Comparison of primary and secondary esophageal peristalsis in humans: effect of atropine. Am 7 Physiol 1991; 260: G52-7.

22 Hollis JB, Castell DO. Effect of dry swallows and wet swallows of different volumes on esophageal peristalsis. $\mathcal{F}$ Appl Physiol 1975; 38: 1161-4.

23 Janssens J, Valembois P, Hellemans J, Vantrappen G, Pelemans $W$. Studies on the necessity of a bolus for the progression of secondary peristalsis in the canine esophagus. progression of secondary peristalsis in

24 Blank EL, Greenwood B, Dodds WJ. Cholinergic control of smooth muscle peristalsis in the cat eophagus. Am $\mathcal{F}$ Physiol 1989; 257: G517-23.

25 Vanek A, Diamant N. Responses of the human esophagus to paired swallows. Gastroenterology 1987; 92: 643-50.

26 Gidda JS, Buyniski JP. Swallow-evoked peristalsis in opossum esophagus: role of cholinergic mechanisms. Am $\mathcal{F}$ Physiol 1986; 251: G779-85

27 Massey BT, Dodds WJ, Hogan WJ, Brasseur JG, Helm JF. Abnormal esophageal motility: an analysis of concurrent radiographic and manometric findings. Gastroenterology 1991; 101: 344-54.

28 Dent J, Dodds WJ, Friedman RH, et al. Mechanism of gastroesophageal reflux in recumbent asymptomatic human gastroesophageal reflux in recumbent as Clin Invest 1980; 65: 256-67. 